\title{
ENVIRONMENTAL REGULATION, ABATEMENT, AND PRODUCTIVITY: A FRONTIER ANALYSIS
}

\author{
By \\ Shital Sharma \\ Clark University
}

CES 13-51

October, 2013

The research program of the Center for Economic Studies (CES) produces a wide range of economic analyses to improve the statistical programs of the U.S. Census Bureau. Many of these analyses take the form of CES research papers. The papers have not undergone the review accorded Census Bureau publications and no endorsement should be inferred. Any opinions and conclusions expressed herein are those of the author(s) and do not necessarily represent the views of the U.S. Census Bureau. All results have been reviewed to ensure that no confidential information is disclosed. Republication in whole or part must be cleared with the authors.

To obtain information about the series, see www.census.gov/ces or contact Fariha Kamal, Editor, Discussion Papers, U.S. Census Bureau, Center for Economic Studies 2K132B, 4600 Silver Hill Road, Washington, DC 20233, CES.Papers.List@census.gov. 


\title{
ENVIRONMENTAL REGULATION, ABATEMENT, AND PRODUCTIVITY: A FRONTIER ANALYSIS
}

\author{
by \\ Shital Sharma \\ Clark University, Department of Economics
}

June 2013

Please email any comments to: shsharma@clarku.edu. I am very grateful to my advisor Wayne Gray for his continuous advice, support, and encouragement during this research. I am indebted to my committee members Junfu Zhang and Chih Ming Tan for providing valuable inputs and Carl Pasurka for his insightful comments on an earlier draft of this paper. I also greatly benefitted from discussions with Wang Jin during the course of this research. Finally, I thank numerous conference and seminar participants for helpful comments and suggestions. Disclaimer: Any opinions and conclusions expressed herein are those of the author and do not necessarily represent the views of the U.S. Census Bureau. All results have been reviewed to ensure that no confidential information is disclosed. 


\begin{abstract}
This research studies the link between environmental regulation and plant level productivity in two U.S. manufacturing industries: pulp and paper mills and oil refineries using Data Envelopment Analysis (DEA) models. Data on abatement spending, emissions and abated emissions are used in different DEA models to study plant productivity outcomes when accounting for abatement spending or emissions regulations. Results indicate that pulp and paper mills and oil refineries in the U.S. suffered decreases in productivity due to pollution abatement activities from 1974 to 2000 . These losses in productivity are substantial but have been slowly trending downwards even when the regulations have tended to become more stringent and emission of pollutants has declined suggesting that the best practice has shifted over time. Results also show that the reported abatement expenditures are not able to explain all the losses arising out of regulation suggesting that these abatement expenditures are consistently underreported.
\end{abstract}




\section{Introduction}

The principle of sustainable growth and development has influenced much of the environmental policies that have come into existence in the last three decades in the U.S. The negative externalities that arise from emission of pollutants gives rise to market failure. Enforcement of regulations and policies is required to correct such market failure. The idea that the costs arising from such externalities to the society should be prevented or be borne by the polluters themselves has been a driving force behind these environmental policies. Since the establishment of the U.S. Environment Protection Agency (EPA) in 1970, the regulations put in place have been increasingly stringent on the environmental standards they set over time. For instance, the Clean Air Act was initially introduced in 1963. Since then it has been amended three times in 1970, 1977, and 1990 making sweeping changes to the kinds of emissions that are regulated and how these regulations are enforced. Similarly, the Clean Water Act, the basis for which was founded in 1948, has also been amended multiple times in 1972, 1977, 1981, and 1987 each time tightening the control on the type and amount of emission allowed into the environment. This has no doubt accrued much benefit to the society within the U.S. in the form of reduced morbidity, increased recreational opportunity, cleaner living environment, increased ecosystem vitality, and possible increased land values (Palmer, Oates, and Portney (1995)). At the same time, concerns have also been raised as to whether these benefits are worth the cost of such regulations. In addition to the direct costs of pollution abatement, proponents of this view have blamed stifled economic growth, decline of labor and capital productivity as well as loss of jobs on such increasingly stringent environmental regulations.

The productivity slowdown during the 1970s, which followed the introduction of a series of environmental regulations for pollution abatement, raised questions on whether some of the slowdown could be attributed to these regulations. The issue naturally garnered interest among policymakers as productivity is related to a wider concern for economic performance including inflation, growth, and unemployment. Shadbegian and Gray (2005) point to the fact that the direct costs of pollution abatement have increased from \$ 7 billion to \$ 18 billion between 1973 and 1993 as measured by the Pollution Abatement Costs and Expenditures (PACE) Survey. Although this is a negligible share of operating costs in manufacturing, this is a resource which could potentially be used on productive inputs. 
Such concerns have led many studies to examine the costs of pollution abatement over the years finding varying degree of impacts on productivity. While research like Denison (1979) that uses abatement cost survey data and studies like Gray (1987) and Barbera and McConnell (1986) that use industry level data have found some effect of regulation on productivity, studies using plantlevel data like Gollop and Roberts (1983), Gray and Shadbegian (2002), Shadbegian and Gray (2005), Färe et al. (1989), and Boyd and McClelland (1999) find even greater declines in productivity due to regulations. Brännlund, Färe, and Grosskopf (1995) was among the initial empirical studies that explored the effect of regulation on profitability of plants using nonparametric Data Envelopment Analysis (DEA) ${ }^{1}$. Some other contributions to the literature using similar methods include Boyd and McClelland (1999), Färe, Grosskopf, and Pasurka (2007), Shadbegian and Gray (2006), and Aiken et al. (2009) all of which have found varying degrees of effect of regulation on productivity.

The main focus of this research is to study the link between environmental regulation and plant level productivity in two U.S. manufacturing industries: oil refineries and pulp and paper mills using DEA models. Data on abatement spending, emissions and abated emissions will be used in different frontier models to study outcomes on plant productivity when emissions are regulated and unregulated. Brännlund, Färe, and Grosskopf (1995) and Aiken et al. (2009) both suggest in their papers that the effect of regulation would be observed better if data at the onset of regulation was available and that their results may have been affected by data constraints. To overcome such constraints, this research uses plant-level abatement spending data between 1974 and 1994 from the U.S. Environmental Protection Agency's PACE survey. This will provide information on plant productivity in the early stages of environmental regulation ${ }^{2}$. In addition to using data on initial years of regulation in the U.S., the paper will also be using a twenty year panel on the pulp and paper and oil refining industries obtained from the Annual Survey of

\footnotetext{
${ }^{1}$ Data Envelopment Analysis (DEA) was proposed by Farrell (1957) and later operationalized by Charnes, Cooper, and Rhodes (1978)Variable returns to scale to the estimation method was later added by Banker, Charnes, and Cooper (1984). The non-parametric method generates a production frontier from the data using a combination of the most efficient plants within the data. All other plants are then compared to the frontier to estimate their efficiency.

${ }^{2}$ Environmental Regulations have been around since the 1940s but the bulk of regulations we see today such as The Clean Air Act and The Clean Water Act were introduced and enforced starting around 1970s when EPA was established. This brings the data used in this paper closer to the time when the costs of regulations started rising considerably making the study pertinent.
} 
Manufactures and Census of Manufactures, allowing a comparison of changes in productivity in response to regulation over time.

Furthermore, the PACE survey also contains data on emission of solid waste and abated emission of certain pollutants, Particulate Matter (PM) and Sulfur Dioxide (SO2), from 1974 to 1982. A separate model is used to study the effect of regulation by allowing for joint production of plant output and abatement of emissions. Finally, measures of water pollution from the Permit Compliance System (PCS) namely Biological Oxygen Demand (BOD) and Total Suspended Solids (TSS) and measures of solid waste emission from EPA's Toxic Release Inventory (TRI) are also obtained for the period 1994 to 2000. Analysis of productivity in existence of regulation using this data sheds light on how the effect of regulation on productivity behaves over a longer period of time. It also allows us to extend the general results of the research beyond the first 20 years in which PACE data is being used for the analysis.

The premise of the study is that environmental regulation causes plants to make abatement expenditures to reduce their pollution emission. Such an increase in abatement spending looks like an increase in the plants' use of productive inputs, without a corresponding increase in output, causing a decline in productivity. The DEA model can test for this decline by comparing productivity measures obtained using the data for the regulated regime to a hypothetical productivity measure for the same plants if they were unregulated. The productivity measures themselves are obtained in the analysis by solving a series of linear equations.

The rest of the research is organized as follows. Section II reviews the literature and outlines the possible contributions this research makes. Section III outlines the empirical estimation methods used for analysis in this research. Section IV describes the data. Section V presents the empirical results of the regulation-productivity relationship and costs of pollution abatement. Finally, section VI concludes. 


\section{Literature Review}

In the past few decades, many academic studies have examined the regulation-productivity relationship. These studies vary by the methodology they employ, the data they use, and the results they find. Denison (1979) uses a growth accounting approach assuming that productivity is affected due to resources moving away from productive inputs to abatement inputs. The study uses abatement costs survey data and finds that the average annual impact of regulation on productivity ranges from .05 to .22 percentage points between 1967 and 1978. A similar study is also conducted by Norsworthy, Harper, and Kunze (1979) assuming that the labor productivity for non-abatement capital decreases as investment shifts to abatement capital. The paper finds that a decline in non-abatement capital formation lead to productivity decline. A time series regression is used by Christainsen and Haveman (1981) to study how regulation affects growth in labor productivity in the U.S. Results suggest that 12 to 21 percent of the decline in productivity growth of labor can be explained using regulations for the period from 1973 to 1977. Greenstone (2002) and Greenstone, List, and Syverson (2012) find that plants in the nonattainment counties are regulated more and also have a lower productivity compared to those in the attainment counties.

Gray (1987) uses parametric econometric estimation techniques with Occupational Safety and Health Administration (OSHA) and EPA information on regulation enforcement from the entire manufacturing sector and compliance costs to find that about 30 percent of the productivity slowdown can be attributed to regulations. Similar effects have also been found by Barbera and McConnell (1986). Using data on four specific industries, the paper finds a significant (negative) effect of regulation on productivity in three industries - paper, chemicals, and primary metals.

Effects on plant-level productivity growth due to restriction on sulfur dioxide emission is studied by Gollop and Roberts (1983) using data from the electric power plants from 1973 to 1979. Results indicate that production costs considerably increased due to the restrictions placed on emissions. Plant-level study of the impact of regulation on productivity for three specific industries - paper, steel, and oil for the period between 1979 and 1990 was carried out by Gray and Shadbegian (2002). Results indicate that plant productivity levels as well as productivity growth rates are lower for plants that face stricter regulation. The same data is used by 
Shadbegian and Gray (2005) to study how abatement costs affect productivity. Results indicate that plants in different industries vary in their response and that even plants within the same industry show varied responses to increased abatement costs. The heterogeneity in response derives from multiple factors including plant-technology used in production and whether abatement is done using a change in production process or using an end-of-line method. Results also indicate that abatement inputs contribute little or nothing to production. Plants that spend more on abatement within the paper industry are also found to have a lower productivity by Gray and Shadbegian (2003). Moreover, the paper also suggests that the technology of production and plant vintage affects how sensitive productivity is to abatement costs.

A similar study on oil refineries, Berman and Bui (2001), finds that regulation does not have a significant negative effect on productivity. On the contrary, the paper suggests that monetary costs of abatement may overstate the economic cost of abatement since abatement might potentially increase productivity.

Brännlund, Färe, and Grosskopf (1995) is among the initial empirical studies that explores the effect of regulation on profitability of firms using a DEA model that includes undesirable output. Results obtained using this model show an increase in profitability of the firms under analysis rather than a reduction. The authors attribute this peculiar result to the circumstance such that data on regulations is only available for one year and that the stipulated amount of regulated emission does not change for the period under analysis for most firms. In addition the authors point out that the firms might have already adjusted to these regulations on emission prior to the period under analysis. The authors do find however, that the effect of regulation is higher for larger plants compared to smaller ones.

A study on similar lines is also conducted by Färe, Grosskopf, and Pasurka (2007). The analysis is conducted for 92 coal fired power plants in the U.S. from 1985 to 1995. Though these results indicate that productivity growth in the regulated plants are slightly lower than in the unregulated plants, the results from the two analyses are not found to be significantly different from each other. The authors indicate that the somewhat uncharacteristic results were obtained because a change in the quality of an input the plants used due to $\mathrm{SO}_{2}$ regulations led to a shift of the 
frontier. This change in quality of the input could not be accounted for in the study because of data constraints. This suggests that a more complete data source could potentially provide additional information on the regulation-productivity relationship.

Boyd and McClelland (1999) use plant level abatement cost data for the paper industry in the U.S. to look at how capital constraint affects productivity. Confidential plant level data from the US Census Bureau, primarily the Longitudinal Research Database (LRD) and the PACE survey as well as emissions data from the U.S. EPA are used. Results indicate that the constraint on productive capital created by having to invest on abatement capital reduces productive efficiency by about three percent.

A similar study on an industry-level dataset is conducted by Aiken et al. (2009). The paper takes data from four countries - Japan, U.S., Netherlands, and Germany, and conducts an analysis of reduction in efficiency due to an increase in the pollution abatement costs in several industries. Results indicate relatively small differences in productivity growth for the regulated and potentially unregulated industries. A reason for this, as pointed out by the authors, is that the capital investment for productive as well as abatement capital grew at very similar rates for the period of the study. It is suggested that the use of data at the onset of regulations might show a relatively larger effect of regulation on productive efficiency.

Some concerns have been raised regarding the PACE data in its ability to completely capture information on abatement expenditures where production process change takes a larger share of abatement efforts relative to end-of-pipe abatement expenditures by Becker and Shadbegian (2007). Nonetheless, it would be expected that plants use larger amounts of abatement inputs initially as they make adjustment to their production processes to comply with new regulations. Thus, additional analysis with earlier data might be able to show a larger impact of abatement costs on productivity. 


\section{Methods of Estimation}

This research employs the Data Envelopment Analysis (DEA) method to study the effect of environmental regulations on productivity. The DEA method constructs a frontier using the linear combination of the most efficient production points in the data and then measures inefficiency of other production points as the distance from these points to the frontier. Such distance is measured using various different types of distance functions, the most common of which is the Shephard's distance function (Shephard, Gale, and Kuhn (1970)). Among the range of distance function approaches available to study the regulation-productivity relationship ${ }^{3}$, the directional distance function approach (Chung, Färe, and Grosskopf (1997)) is used here.

For the problems considered in this research, the following general definition of the production technology is used in describing all estimation models. Assume that there are $n$ firms with firm $\mathrm{j}$

$(j=1, \ldots, n)$ that uses $p$ inputs $x_{i j}(i=1, \ldots, p)$, produces $q$ desirable outputs $y_{r j}(r=1, \ldots, q)$, and $\mathrm{t}$ undesirable outputs $\mathrm{z}_{\mathrm{sj}}(\mathrm{s}=1, \ldots, \mathrm{t})$. The production technology can then be modeled using the output set $\mathrm{P}(\mathrm{x})$ denoted as: $P(x)=\{(y, z): x$ can produce $(y, z)\}$

Furthermore, the following assumptions are made:
a. if $(y, z) \in P(x)$ and $\hat{y} \leq y \Rightarrow(\hat{y}, z) \in P(x)$
b. if $(y, z) \in P(x)$ and $0 \leq \theta \leq 1$, then $(\theta y, \theta z) \in P(x)$
c. if $(y, z) \in P(x)$ and $z=0$, then $y=0$

The first assumption imposes strong disposability of the desirable output such that the output $y$ can be disposed of at no cost to the plant. The second assumption imposes the weak disposability of the undesirable output such that a reduction in $\mathrm{z}$ by the factor $\theta$ comes at a cost of a reduction in $y$ of the same factor $\theta$. The final assumption enforces null-jointness on the production of the two outputs y and $\mathrm{z}$. This means that a firm cannot produce the desirable output y without producing the undesirable output $\mathrm{z}$. The directional distance function for output set $\mathrm{P}(\mathrm{x})$, can be

\footnotetext{
${ }^{3}$ Some other DEA models that have been used to study similar issues are the hyperbolic model introduced by Färe et al. (1989) and the linear transformation model introduce by Seiford and Zhu (2002) and Seiford and Zhu (2005). Cook and Seiford (2009) provide and extensive review of how the DEA estimation methods have developed over the past 30 years.
} 
defined as: $D_{0}^{d}(x, y, z: g)=\sup \{\beta:((y, z)+\beta g) \in P(x)\}$. Note that this distance function scales the desirable and undesirable outputs according to the direction vector $g$ allowing more flexibility to researchers in how they want to measure efficiency.

Now to first study how regulation affects productive efficiency using abatement cost data, it is convenient to decompose the plant's input vector into two sub vectors, $x=\left(x^{n o}, x^{o}\right)$ where $x^{\text {no }}$ and $x^{o}$ represent vectors of non-abatement inputs and abatement inputs respectively. As regulations are introduced, plants are required to divert some of their resources from nonabatement inputs to abatement inputs. To evaluate how this affects efficiency, the following two measures are calculated with the assumption of constant returns to scale ${ }^{4}$.

$$
\begin{aligned}
\text { Model 1: } & \text { E1 }=\max \quad \beta_{a} \\
\text { s.t. } & \sum_{j} \lambda_{j} x_{i j} \leq x_{i a}, \quad i=1, \ldots, p \\
& \sum_{j} \lambda_{j} y_{r j} \geq\left(1+\beta_{a}\right) y_{r a}, \quad r=1, \ldots, q \\
& \lambda_{j} \geq 0, \quad \forall j
\end{aligned}
$$

Model 2: $\quad \mathrm{E} 2=\max \quad \beta_{a}$

$$
\begin{array}{ll}
\text { s.t. } & \sum_{j} \lambda_{j} x_{i j}^{n o} \leq x_{i a}^{n o}, \quad i=1, \ldots, p \\
& \sum_{j} \lambda_{j} x_{i j}^{o} \leq x_{i a}^{o}, \quad i=1, \ldots, p \\
& \sum_{j} \lambda_{j} y_{r j} \geq\left(1+\beta_{a}\right) y_{r a}, \quad r=1, \ldots, q \\
& \lambda_{j} \geq 0, \quad \forall j
\end{array}
$$

Let us first understand the envelopment problem. In Model 1, the parameter $\beta_{\mathrm{a}}=\mathrm{E} 1$ gives us the efficiency score of plant ' $a$ '. $\beta$ in this sense tells us how much output plant ' $a$ ' can increase keeping its input constant just by increasing efficiency. Note that the first constraint of Model 1 requires the inputs of plant ' $a$ ' to be not less than a linear combination of the inputs of the best performing plants. The second constraint requires the output of plant 'a' to be expanded by the factor $\beta$ such that $\left(\mathrm{y}_{\mathrm{a}}+\beta_{\mathrm{a}} \mathrm{y}_{\mathrm{a}}\right)$ is at least equal to the linear combination of the outputs of the best

\footnotetext{
${ }^{4}$ Fare and Knox Lovell (1978) show that choice of returns to scale assumptions can affect the results in DEA analysis. A comprehensive review of the returns to scale literature for DEA models is also found in Banker et al. (2004) Since constant returns to scale is widely used in this type of analysis, this is the assumption chosen for the study. Assuming variables returns to scale does not alter the main findings of the paper.
} 
performing peers in the sample. The intensity vectors $\lambda_{j}(j=1, \ldots, n)$ in the constraints facilitate in constructing the combinations of the inputs and outputs to form the frontier of the production possibility set for efficiency analysis. The last constraint in Model $1 \lambda_{j} \geq 0, \quad \forall j$ imposes constant returns to scale in the model.

The two models presented above differ in that Model 1 assumes that both categories of inputs have the same effect on the production of the desirable output as represented by the first constraint in the linear programming problem. Model 2 is more restrictive and assumes that the productivity of the two categories of inputs differs from each other. Shadbegian and Gray (2005) suggests that non-abatement inputs may be much more productive than abatement inputs. The basic premise of the study thus is that environmental regulation causes firms to make abatement expenditures to reduce their pollution emission. Such an increase in abatement spending looks like an increase in the plants' use of productive inputs, without a corresponding increase in output, causing a decline in productivity. If this premise is incorrect, the more restrictive Model 2 and the less restrictive Model 1 should yield the same result. On the other hand, if it is correct, the two types of inputs would not contribute to productive efficiency equally and Model 2 would yield a different result due to the additional constraint on inputs that is binding.

The ratio of the productivity measures obtained from the two models can be used to calculate the cost of pollution abatement in terms of output loss ${ }^{5}$. To bring the estimation in line with Shepard's distance functions ${ }^{6}$, we calculate the following:

Output Loss $=1-\frac{\left(\frac{1}{1+E 1}\right)}{\left(\frac{1}{1+E 2}\right)}$

\footnotetext{
${ }^{5}$ Note that Models 1 and 2 are using the difference in the use of abatement inputs relative to non-abatement inputs in order to identify the effect of regulation. If $a x$ and nax are used in identical proportions by the plants, i.e. if $a x=5 \%$ of nax for all plants, E1 and E2 will produce identical results even if regulations are enforced and plants are facing a cost due to it. This however, is not a serious limitation since literature points out that enforcement of regulation is varied across plants. See Ringquist (1993), Gray and Shadbegian (2003), and Shimshack and Ward (2005)

${ }^{6}$ The relationship between efficiency scores from the directional distance function approach and the Shephard's distance function approach is $D_{0}=\left(\frac{1}{1+D_{0}^{d}}\right)$ as presented in Färe and Grosskopf (2000)
} 
If the measure of output loss is 0 , then regulation will have had no effect on productive efficiency. If on the other hand the measure of output loss is greater than 0 , the value indicates a measure of loss of productivity due to regulation.

Here, E2 is expected to produce higher efficiency scores since the abatement and non-abatement inputs are assumed to contribute to production of the desirable output y separately. Alternatively, the efficiency score E1 is expected to produce lower scores since the sum of both abatement and non-abatement inputs are seen to contribute to the production of the same output y together. Model 1 in this sense assumes what would have happened had the regulation not been in place. All the resources that plants have would be spent on non-abatement inputs that are more productive since plants would not have had to spend on abatement inputs.

Note that the models presented above and the ones to follow do not study the effect of any one particular regulation on productivity. The study assumes that regulations are already in place and that the plants are already complying with all of these regulations. The basis of the study is to create a hypothetical unregulated regime by removing the restrictions placed on plants by such regulations to study what would happen had these regulations not been in place. Thus the cost of regulations measured here represents an overall cost rather than the cost of a specific regulation.

The next estimation method deals with measuring the effect of regulation on productivity using data on emission of pollutants. Given the production technology previously defined, the weak disposability assumption imposes a cost of loss of output when the emissions are restricted. The evaluation of such a loss of output is made by comparing the efficiency measure from Model 1 to the one presented below. Model 1 assumes that there is no restriction on the production of the undesirable output $\mathrm{z}$. This model as such allows plants to emit as much pollutants as they want.

$$
\begin{array}{cl}
\text { Model 3: } & \text { E3 } \quad \max \quad \beta_{a} \\
\text { s.t. } & \sum_{j} \lambda_{j} x_{i j} \leq x_{i a}, \quad i=1, \ldots, p \\
& \sum_{j} \lambda_{j} y_{r j} \geq\left(1+\beta_{a}\right) y_{r a}, \quad r=1, \ldots, q \\
& \sum_{j} \lambda_{j} z_{s j}=z_{s a}, \quad s=1, \ldots, t \\
& \lambda_{j} \geq 0, \quad \forall j
\end{array}
$$


Model 3 on the other hand imposes a restriction on the amount of emission. This restriction implies that the amount of pollutants the plants emit is exactly equal to the amount that they are required to emit under regulation. This restriction is also associated with a weak disposability of the two outputs.

It has to be understood that the assumption made in this restriction is not without its limitations. In an ideal world, instead of assuming that the pollutants plants emit are exactly what they are required to emit, information on the exact plant-level requirements on emissions could be used. However, given that such information is not available, an assumption that plants are emitting what they are supposed to is made. This is problematic though when plants are in reality noncompliant or over-compliant. When a plant is non-compliant, it is emitting more than it should and thus the true cost of regulation is hidden. In such cases, only the realized cost due to abatement can be observed. Thus the cost measured here is only a lower bound of the cost of regulation. On the other hand, if a plant is over-compliant, the observed level of emission could be much less than what regulation requires it to be for that plant. This would over-estimate the cost of regulation since the observed cost of abatement would be much higher than what the regulation requires it to be. Shimshack and Ward (2008) however, suggests that over-compliance in plants may be caused by enforcement of regulations. Hence, any cost of abatement observed from over-compliance can be argued to be representing the actual cost of regulation. In cases like these, caution has to be implemented in the interpretation of results. The cost of regulation and cost of abatement will thus be used interchangeably on all following discussions. Subsequently, the loss in output due to regulations can then similarly be calculated as:

Output Loss $=1-\frac{\left(\frac{1}{1+E 1}\right)}{\left(\frac{1}{1+E 3}\right)}$

The measure of output loss, if greater than 0 , represents a measure of the output lost due to the imposition of regulation. For instance, if the measure of output loss is 0.11 , then the amount of output lost would be about $11 \%$ of current outputs. 
Though the measure of output loss in the two estimation methods presented above look the same, they imply two different things. The measure of output loss in equation (iii) implies the loss of productive efficiency due to a diversion of resources from non-abatement inputs to abatement inputs. However, this is only a part of the total economic cost of pollution abatement. There might be other costs the plants incur such as loss of output due to plant down time when the abatement capital is being installed, loss in output due to constraints on the choice of the production process, or reduced productivity of other non-abatement inputs. These other costs are not included in the output loss measured due to diversion of resources. However, the imposition of weak disposability in the estimation method presented in Model 3 does include these costs. Since this loss is measured from restrictions on the amount of emissions arising out of environmental regulations and not from just diversion of resources, the output loss in equation (v) represents a more comprehensive measure of the economic costs of pollution abatement.

There is one caveat to this type of measurement of efficiency though. Frontier plants face some loss due to regulations if they are in the frontier for a regulated regime but not in the frontier for the unregulated regime ${ }^{7}$. But if a plant happens to be on the frontier for the regulated as well as the unregulated regime then the loss experienced by the plant because of regulations is not observed from the models used in the analysis. For instance, the DEA estimate can consider a plant most efficient on both regimes even if it is spending $\$ 10,000$ on abatement. While the loss estimate indicates that there is no loss from regulation, there could be some opportunity cost to the $\$ 10,000$ spent on abatement by the plant which is lost in the construction of the frontier ${ }^{8}$. In this way, the efficiency loss measured using the DEA models are only a lower bound of the true losses incurred by the plant.

Finally, a similar model can be developed to measure the cost of pollution abatement using data on abated emission. The only change to the model would be to consider the abated emission a

\footnotetext{
${ }^{7}$ All frontiers for the purpose of this study are constructed using contemporaneous data in each year. However, sequential data by year and window analysis can also be used to obtain frontiers that estimate smoother efficiency scores. For a comprehensive discussion, see Asmild et al. (2004)and Shestalova (2003).

${ }^{8} \mathrm{~A}$ plant on the frontier for both regulated and unregulated regime implies that the frontier overlaps and that there is no opportunity cost of resources spent on emission reduction. However, it has to be recognized that the production model specified is by no means exhaustive and there could be a lot of excluded unobserved inputs that affect plant productivity that could potentially use the resource spent on abatement to increase plant output.
} 
'neutral' output rather than a desirable or undesirable output. Although more abated emission is better and it is strongly disposable, it cannot be considered a 'good' or 'desirable' output for two reasons. First, since the estimation takes an output approach to efficiency measurement, any increase in abated emission keeping inputs constant would be considered an increase in desirable output and measured as efficiency. Since such increase is not considered in traditional efficiency measurements, it makes more sense to consider abated emission a 'neutral' output and not measure its contribution to efficiency here. Second, a desirable output for a plant should be one that a plant would try to maximize when it is left alone. Since the production of abated emission is assumed to occur mostly due to regulations and since in its absence plants would produce much less abated emission, considering it a purely desirable output does not make sense ${ }^{9}$. The output loss from abatement can then be measured from the difference in efficiency arising out of the production or non-production of abated emissions.

One common criticism of the type of analyses conducted above is that when plants are compared to each other to get a measure of efficiency, some unobserved variables like management style of plants, age, and location of plants are not included in the analysis. The considerable heterogeneity in these unobserved variables across plants and their potential effect on a plant's efficiency leads to an omitted variable bias when such information is left out of the analysis. Morgenstern, Pizer, and Shih (2001) prescribes a plant fixed-effects model to account for such omitted variable bias. The paper explains that while a fixed effects approach does away with a lot of variation across plants, this is necessary if there is reason to believe that the variation in output is being caused by variables that are not included in the analysis.

Gray and Shadbegian (2002) raise concerns about the use of fixed-effects. The concern here, initially raised by Griliches and Mairesse (1995), is that if the variation in the explanatory variables within plants, especially abatement expenditures, is mostly measurement error then using a fixed-effects model removes most of the actual variation in the data that is found across plants leaving only noise which would bias the estimate parameters towards zero. Thus, the choice between a fixed-effects model and a pooled or cross-sectional model hinges on whether

\footnotetext{
${ }^{9}$ Note that this treatment of abated emissions as a 'neutral' output only works if the efficiency measure is ignoring changes in the undesirable output production. One could look at the effect of net bad output production in cases where data on both abated emissions and emissions are available.
} 
the analysis is more likely to suffer from measurement error in the data or an omitted variable bias.

Since there is no reason to believe that the data suffers from systematic within-plant measurement error, and there is an obvious problem of omitted variables, a fixed-effects approach is taken next. Instead of constructing a frontier from a cross section of plants in each year, a frontier is constructed using multiple years of data from each plant using the PACE abatement spending data. Efficiency is then measured for the regulated and unregulated regime using estimation Models 1 and 2 for each plant using multiple years of data. This approach is similar to the fixed effects since the frontier for each plant consists of observations on the same plant over multiple years. Thus just the within-plant variation in data is used to measure a plant's efficiency in any given year. A measure of loss can then be calculated using equation (iii). The results for all of the estimation methods outlined above are presented in Section V. 


\section{Data}

This study uses data from various sources to estimate the regulation-productivity relationship. Due to the non-parametric nature of the study and the estimation methods used, information on plant-level outputs, inputs, spending on abatement, as well as amount of pollutants emitted by each plant is required. Since information from varied facets of a plant's production is required, the study uses different samples for each estimation method on each industry. The Annual Survey of Manufactures (ASM) and Census of Manufactures (CMF) from the U.S. Census Bureau are the main source of the plant output and input information. In addition, data on abatement expenditures are obtained from the Environmental Protection Agency's (EPA) Pollution Abatement Costs and Expenditures (PACE) Survey. Data on emissions and abated emissions for earlier periods is obtained from the PACE survey as well. A separate set of emissions data for a later period is obtained from EPA's Permit Compliance System (PCS) and Toxic Release Inventory (TRI) database. In addition, data from Gray and Shadbegian (2004) is used to calculate the benefits accruing from reduction in particulate emissions.

The study includes plants from two industries in this analysis - pulp and paper mills and oil refineries. These two industries are among the heaviest emitters of both air and water pollutants in the U.S. Pulp and paper mills are large emitters of air pollutants like particulate matter (PM) and sulfur dioxide (SO2), and water pollutants like biological oxygen demand (BOD) and total suspended solids (TSS) which are generated chiefly during the pulping process. Similarly, oil refineries also emit a large amount of pollutants chiefly during the process of catalytic cracking and cooling. Such high intensity of pollution means that the effects of regulation can be observed more clearly.

Data on outputs and inputs for all years for both pulp and paper mills and oil refineries are obtained from the ASM and the CMF. Output (y) is measured using the total value of shipments, which is adjusted for inventories and work in progress. The vector of inputs (x) contains four inputs: labor (L), materials (M), energy (E), and capital (K). Labor input is measured as total production hours. Materials input is represented by the sum of dollar expenditure on materials, resale and contract work. Energy input is the sum of dollar expenditure on fuel and purchased electricity. The measure of plant-specific real capital stock is based on the standard perpetual 
inventory method (PIM) that accounts for new investments as well as disposals and depreciation for each year, applied to the ASM and CMF data on new investment for each plant. ${ }^{10}$ All the variables used for inputs and outputs except for labor are measured in 1987 dollars. To consider the impact of regulation on productivity using abatement costs, capital expenditure and operating costs on pollution abatement (also measured in 1987 dollars) is obtained from the PACE survey for the period from 1974 to 1994. This constitutes the first set of samples that makes use of the estimation method presented in Models 1 and 2.

Data on emissions is obtained from various sources for various periods. Data on solid waste emissions is obtained from PACE survey for the period from 1974 to 1982. This emission is measured in tons per year. Measures of water pollution from the Permit Compliance System (PCS) namely biological oxygen demand (BOD) and total suspended solids (TSS) and measures of solid waste emission from EPA's Toxic Release Inventory (TRI) measured in tons per year are obtained for the period 1994 to 2000. These emissions data are then combined with the input and output information from ASM and CMF for the estimation method presented in Models 1 and 3. In addition, the PACE survey also contains data on abated emission of Particulate Matter (PM) and Sulfur dioxide (SO2), from 1974 to 1982. In order to compare the cost of regulation to the benefits derived from it for the pulp and paper mills, benefits data from Gray and Shadbegian (2004) is used. This data measures the benefits of reduction in particulate matter pollution using an air dispersion model, SLIM-3, which calculates the impacts of pollution from each plant to the population surrounding it. In this manner, a plant-specific marginal benefit measure is derived for reductions in particulate matter at each plant.

One additional assumption that is made in the DEA approach is that the technology available to all plants under analysis is the same. This is done to ensure that plants at the frontier and plants below it are comparable. If the plants under the frontier do not have access to technology being used by the plants at the frontier, a comparison of the two is not going to yield a meaningful result as the plants below the frontier would not achieve the level of output or the level of efficiency achieved by those at the frontier. To confirm that this assumption is maintained, only those plants are considered in the samples that have access to the same technology. In case of the

\footnotetext{
${ }^{10}$ I would like to thank John Haltiwanger for making his version of these data available to other researchers.
} 
paper industry, paper mills that incorporate a pulping process are included in the sample. In the case of oil refineries, those that include catalytic cracking are included in the sample. In addition to ensuring that the plants in our sample are using the same technology, this sample construction also focuses on those technologies that are considered to be more polluting than others.

Finally, since outliers are a major concern for DEA analysis especially when they enter the frontier against which all other plants are compared; such outliers are excluded from the analysis. The method proposed in Wilson (1993) is used to detect such production points that have a very low probability of occurrence. This method prescribes a statistic that measures the proportion of geometric volume spanned by a subset of data obtained by deleting ' $n$ ' observations relative to the volume spanned by the entire dataset. The possible outliers are selected by how this statistic moves closer to one as ' $n$ ' changes. Once the observations with a low probability of occurrence are identified, it is up to the researcher to determine whether they should be excluded from the sample with additional analysis.

In the case of this research, no outliers were identified in most of the samples used. Only the sample of pulp and paper mills that use PACE data turned up some plants that tended to have a low probability of occurrence. A closer examination also showed that while such plants produced an average output that was about equal to the average output of other plants in the sample, their reported pollution abatement expenditures were zero in most of the years. In addition, they used an average input that was less than $60 \%$ of inputs used by other plants on average in the sample leading them to become immensely more efficient than other plants in the sample. Such plants were thus removed from the sample before the analysis was conducted.

Summary statistics for the variables used in the analysis are presented in Tables 1 through 3 . All variables are reported in the millions of 1987 dollars except for the production workers which is measured in thousands of hours. Table 1 provides summary statistics for the economic variables used in the analysis for the pulp and paper mills and oil refineries respectively. The samples used for these summary statistics are samples used to solve models 1 and 2 that use abatement spending data in the estimation methods section. Other samples using emissions and abated emissions data are very similar to the ones presented in Table 1 and thus are not provided here. 
It can be observed from the Table 1 that while the values for output- Y, capital - K, energy - E, and materials - M grew over the sample period, labor - L did not. A similar upward trend can also be observed for pollution abatement operating costs (PAOC). Pollution abatement capital expenditure (PACE) seems to have declined relative to the large abatement capital investments required in the early 1970s. For instance, installing a smokestack scrubber is not a regular annual expense for a plant but a one-time investment.

Tables 2 and 3 provide summary statistics for the pollutants emitted and the amounts of pollutants abated in millions of tons. ${ }^{11}$ It can be observed from Table 2 that the amount of abated emission of particulate matter for the sample period has increased. This increase along with increase in abatement spending from previous tables indicates some effect of regulation on emissions and abatement. This is further enforced by figures in Table 3 that report the amounts of emission of other pollutants in both industries in thousands of tons. The emission of solid waste in Table 2 however is also increasing. Such increases however do not suggest that this emission is not affected by regulation. It could be argued that the figures might have been higher had the regulation not restricted the emission of such solid waste. In addition, disposal of solid waste was not as heavily regulated as air or water emission in the initial years as long as the solid waste was disposed of properly.

According to Table 3, the emission of biological oxygen demand (BOD) and total suspended solids (TSS) for the paper industry have both decreased over the sample period. Similarly, BOD and TSS for oil refineries also show a decline. Waste measured from toxic release inventory (TRI) for pulp and paper mills however has slightly increased over the period.

\footnotetext{
${ }^{11}$ While the analysis was conducted for both Paper and Oil Industries using abated PM, abated SO2, and solid waste emissions from the PACE survey, results and summary statistics are only provided for emissions and abated PM for the pulp and paper mills. All omitted results and summary statistics are qualitatively very similar.
} 


\section{Regulation-Productivity Relationship and Cost of Pollution Abatement}

To understand the regulation-productivity relationship, we estimate efficiency measures by solving the models presented in section III. The resource constraint or the disposability assumption made within the models allows a comparison of the efficiency scores for plants when they are regulated and when they are not. How a plant's behavior might change due to restrictions put on it by these assumptions allows us to observe what impact environmental regulations might have had on these plants. The difference between the two efficiency scores that is measured within each problem is implied in the loss measure calculated. This loss measure represents the amount of output forgone in order to comply with regulations. The impact of regulation can thus be observed using these efficiency scores and the loss measure calculated.

One of the ways inefficiency arises from environmental regulations is by the diversion of resources from production to use as abatement inputs. Models 1 and 2 present the linear programming problem to measure this efficiency loss. It has to be borne in mind that the models are only measuring the effect of abatement capital on current period outputs. In reality, capital is observed to have a long term effect on outputs and productivity that extend beyond the first year. Furthermore, Shadbegian and Gray (2005) also points to the possibility that the PACE survey may be underreporting the abatement expenditures. For instance, survey respondents may leave out costs that are more difficult to quantify such as time spent by workers on abatement related tasks. In this sense, the results presented herein may only capture a lower bound for the effect of abatement inputs on productivity.

Estimation using Model 1 includes measures of inputs and outputs described in the data section. However, the abatement expenditures are assumed to be included within these measures of inputs. This assumes that the abatement inputs contribute to production of outputs just like nonabatement inputs. Model 2 on the other hand breaks up the real values of abatement inputs (both capital expenditures and operating costs) from the non-abatement inputs and includes them separately in the linear programming problem.

Results for this analysis are presented in Figures 1 through 3 . Since the estimations are made with an output approach, results for the efficiency score of a plant is obtained by measuring its 
potential to increase output without increasing inputs compared to its best performing peers. It can be observed from Figure 1 that the average inefficiency for the pulp and paper mills under the unregulated regime ranges between 13 and 27 percent; since the efficiency scores average between 73 and 87 percent. This efficiency score is calculated for plants under the assumption that all inputs contribute to productivity equally. Figure 1 also presents the average efficiency scores when the assumption on inputs is changed such that abatement and non-abatement inputs contribute separately to productivity. When this more restrictive assumption is made, the efficiency scores change to an average of between 79 and 90 percent. Given the same inputs and outputs, the higher efficiency score obtained using the more restrictive assumption that is binding shows that abatement inputs do not contribute to production as much as non-abatement inputs do.

The output loss measure constructed using the difference in the two efficiency scores presented in figure 3 represents the average loss for plants because of regulations which led them to divert their resources from non-abatement inputs to abatement inputs. This loss measure for the pulp and paper mills averages from 3 to 10 percent. Thus for a plant that has an average output of $\$ 215$ million in the regulated regime in 1974, an average loss of 8\% could be about $\$ 17.2$ million worth of output lost because of regulations that required it to spend an average of about $\$ 9$ million on abatement inputs.

Results for a similar analysis on oil refineries are presented in figures 2 and 3. Similar to the results from the pulp and paper mills the average output loss for oil refineries range between $2 \%$ and 9\%. Results indicate regular average efficiency losses for oil refineries and pulp and paper mills due to resource diversion between 1974 and 1994 that are quite substantial. It is also worth noting that these losses seem to be slightly trending downward over time. This regularity and relative consistency of results is partly also due to the removal of outliers. The method proposed in Wilson (1993) was used to detect production points that have a very low probability of occurrence. In addition, the inclusion of such plants in the analysis also results in huge inefficiencies for other plants in the sample and the loss measure becomes biased. Removal of such outliers for this analysis tended to make the loss measures more stable and removed any such bias arising out of influential data points. 
The second method of estimation explained using Models 1 and 3 for this analysis uses data on emission of various pollutants over two different time periods. First, information on emission of solid waste is available from the PACE survey for 1974-1982. Second, emission of water pollutants like BOD and TSS as well as emission of toxic releases, TRI, is available from EPA's Permit Compliance System and Toxic Release Inventory for the period between 1994 and 2000. Results are presented in Tables 4 to 6.

Table 4 presents results from the analysis using emission data from PACE survey. Whereas the efficiency loss in the previous analysis was measured using resource diversion, the efficiency loss in this analysis is measured using the weak disposability assumption. It can be observed from the table that the average loss for the pulp and paper mills range from 3 to 7 percent. The average loss values for the oil refineries were also very similar ${ }^{12}$. Like the losses observed from the resource diversion models, this loss signifies that the weak disposability assumption that is binding measures the decline in plants' productivity due to regulations.

Results from Tables 5 and 6 can be interpreted similarly. All results show that a substantial productivity loss arises from regulation. Keep in mind that we look at the effect of regulation using one type of emission at a time. More often, plants face regulations on emission of several pollutants at the same time. If we change the sample and add more pollutants within the same analytical framework, the output loss due to regulation is expected to rise.

Finally, there is one more estimation made using the data on abated emissions from the PACE survey to study the effect of regulation on productivity. Weak disposability assumptions similar to the previous models are used to measure the loss in efficiency due to regulation. Results presented in Table 7 indicate that the average loss for the pulp and paper mills from 1974 to 1982 is between 3 and 8 percent. The average loss for the oil refineries for the same period was also very similar ${ }^{13}$. A Wilcoxon signed rank sum test was conducted on each of the regulated and

\footnotetext{
${ }^{12}$ Multiple samples have been used for analysis of regulation-productivity relationship. Most of the samples significantly overlap and results from all analysis are very similar. However, all the results could not be reported because of confidentiality restrictions that govern the use of Census data.

${ }^{13}$ Analysis was conducted for abated emissions of PM as well as SO2 for both pulp \& paper and oil industries. Results have only been reported for abated PM in paper industry for brevity as well as due to confidentiality restrictions. The results for all other analyses were qualitatively similar to the one reported.
} 
unregulated efficiency scores presented in all the results for each year. Results indicate that the two efficiency scores are significantly different from each other.

However, there are some unobserved factors apart from the various inputs used in the analysis above that could affect outputs produced by the plants under analysis. Factors such as plant age, location, and management style could impact the production of outputs as much as the other inputs used in the production process. Since these variables are not included in the estimation models, the efficiency estimates obtained might be biased. That is inputs like abatement spending and productive inputs might be observed to be very inefficient while the inefficiency might actually be arising out of unobserved poor management in the plant or unfavorable location.

To account for this unobserved heterogeneity across plants that affects efficiency, an approach similar to the fixed-effects method is taken. Frontiers are constructed for each plant using observations for the same plant across multiple years. Since data is available on abatement spending over a period of 20 years, the resource diversion model is employed. Once the two efficiency scores are obtained and the corresponding efficiency loss is calculated, it is first averaged within plants and then across the plants to get to an average figure of output loss. ${ }^{14}$ Since Data Envelopment Analysis (DEA) only allows for a comparison of plants with access to same technology and access to technology for plants change over time, an index of technological advancement is generated from the Malmquist-Luenberger Index to control for technological changes within plants across time. ${ }^{15}$ Results for the two industries are provided in Table 8.

Despite using the fixed effects, the first column of Table 8 in the results show that plants do incur losses of output due to regulation. From the last column of Table 8, which shows average losses from the cross-sectional analysis for each industry, it can be seen that the losses obtained

\footnotetext{
${ }^{14}$ Due to the confidentiality restrictions that govern the use of Census data, average output loss for each plant cannot be provided in the results. Instead, a mean loss figure for all plants is provided with a standard deviation. This gives some idea of the distribution of this loss across plants.

${ }^{15}$ The fixed effects approach used for this analysis uses a measure of technological change derived from one DEA estimator as an input to estimate efficiency of plants in another stage. The use of bootstrapping could further increase the statistical efficiency of the results obtained using this method. See Simar and Wilson (2007) for a detailed discussion.
} 
from the fixed-effects approach are much smaller than those obtained from the cross-sectional analysis. However, they are not completely eliminated with the use of the fixed-effect approach. This gives further credence to the results obtained initially that show that environmental regulations lead to productivity losses.

Given the existence of such sizeable productivity losses, a natural question then is how these costs of regulation compare to the benefits of regulation. Such benefit comes in the form of reduced mortality, reduced morbidity, better ecosystem vitality, and a better environment for a sustainable future for human beings. The benefit from reduced mortality is measured here using data from Gray and Shadbegian (2004). This data measures the benefits of reduction in particulate matter pollution using an air dispersion model, SLIM-3, which calculates the impacts of pollution from each plant to the population surrounding it.

It can be clearly seen from Table 9 that the benefits that accrue to the society from reduction in PM10 emissions are far greater (by two orders of magnitude) compared to the costs that the plants incur because of the regulations that restrict the emission of PM10 in each year of the analysis. Though caution is advised in the interpretation of the cost of regulation as only a lower bound and though there are many other costs of regulation such as costs of enforcement to the regulators, these costs cannot offset the benefits that people get from such regulations. Further, the benefits presented above only account for reductions in mortality. Other benefits such as those from reduced morbidity and improved ecosystem vitality would only expand the total benefits that accrue due to environmental regulations.

\section{Conclusion}

In addition to the results (from multiple models and samples) indicating a sizeable effect of regulation on productivity from 1974 to 2000, there are some interesting implications to consider. We can see that while abatement of emission of PM is increasing during the 1974-1982 period and emission of BOD and TSS is decreasing, the loss due to regulation seems to be substantial and slightly trending downwards over time. This implies that while regulation has become more stringent and abatement efforts higher over time, the performance of plants in 
general has become better and even the best performing plants have improved their performance over time. This could also imply that while technological advancements have been made in terms of the production process as well as abatement processes to adjust to increasingly stringent regulations, most plants in the sample have kept pace with the change. This type of change can be further studied using the Malmquist-Luenberger productivity index which can be used to decompose productivity change into efficiency change and technological change.

Earlier, it was also pointed out that economic costs of pollution abatement are obtained from the solution of Models 1 and 3, and that cost of pollution abatement due to resource diversion is obtained from the solution of Models 1 and 2. The effects thus were expected to be larger for analysis that uses emissions data compared to the one that uses abatement spending data. Results on the contrary seem to indicate that costs of pollution abatement due to resource diversion are almost equal to and sometimes larger than the economic costs of regulation. This is because the resource diversion models considered here deal with only one pollutant at a time. A more complete model with simultaneous constraints on multiple pollutants would be expected to generate larger cost estimates.

A final caveat on the interpretation of the results is that the efficiency loss estimates presented in the results can only be taken as a lower bound for the total loss incurred by plants due to regulation. Since inefficiencies arise out of many factors within each plant, a complete analysis of all inefficiencies arising out of regulation is not possible. For instance, a regulation might restrict a plant from choosing a certain production process or a production technology thereby rendering it much less efficient than it could be. Since data is only available for current production process or technology when the plant is regulated, an analysis of its efficiency loss does not incorporate its loss from an alternative technology it could potentially adopt if the regulation had not come into effect.

In summary, this section concludes that pulp and paper mills and oil refineries in the U.S. did suffer decreases in productivity as a cost of pollution abatement from 1974 to 2000 because of regulations. These declines have been slowly trending downward over time even when the regulations have tended to become more stringent, abatement spending has increased, and 
emission of pollutants has declined over time suggesting that the best practice has shifted over time. Since the results consistently show losses arising from the diversion of resources from productive inputs to abatement, it is also prudent to check if this reduction in output is proportional to the increase in inputs caused by the abatement expenditures. Results for this analysis are presented in Tables 10 and 11. Results in Table 10 indicate that the reported abatement expenditures are not able to explain all the losses arising out of regulation in almost every year in the sample. Such output loss that cannot be explained by abatement spending points to the possibility that these abatement expenditures may be consistently under-reported. Though abatement expenditures are able to explain a higher proportion of losses arising out of regulation when the fixed effects approach is used, results in Table 11 indicate that this is not enough to rule out the possibility that abatement expenditures are under-reported.

A test of correlation was also conducted to see if the size of the plants or the efficiency of plants was correlated with the estimated output loss arising out of regulation. For this purpose, the output loss was measured using both the resource diversion model and the emission restriction model. Plant size was measured using the value of output of each plant and the efficiency estimate was derived from the output to the DEA models in the regulated regime. Results indicate that there is little to no correlation between plant size or plant efficiency and the estimated output loss arising out of regulation.

In addition, it is worth noting that while there are costs to plants from environmental regulation, the benefits that accrue to the society from such regulation are much larger than these costs. This provides ample justification for the existence of such regulations and why they are important. Future extensions of this study could look at how such productivity decreases behave over time using the Malmquist-Luenberger productivity index or study whether such productivity decreases are statistically significant by constructing confidence intervals for the efficiency estimates. A possible extension could also test to see whether such productivity decreases are consistent when the direction of efficiency measurements is altered to include performance on emissions within the efficiency estimates. 
Table 1. Summary Statistics ${ }^{16}$

\begin{tabular}{cccc|ccc}
\hline \multicolumn{2}{c}{ Pulp and Paper Mills (68 Obs. per Year) } & \multicolumn{2}{c}{ Oil Refineries (34 Obs. per Year) } \\
\hline & Mean in 1974 & SD in 1974 & $\begin{array}{c}\text { \% Growth in } \\
\text { Mean 1974- } \\
\text { 1994 }\end{array}$ & Mean in 1974 & SD in 1974 & $\begin{array}{c}\text { \% Growth in } \\
\text { Mean 1974- } \\
\text { 1994 }\end{array}$ \\
\hline Y & 215.02 & 96.57 & 48.68 & 1175.36 & 759.62 & 62.49 \\
K & 87.22 & 45.19 & 181.98 & 245.18 & 135.01 & 148.15 \\
L & 1.60 & 0.98 & -2.50 & 1.31 & 0.82 & 9.16 \\
M & 102.56 & 45.72 & 43.80 & 1149.92 & 682.04 & 42.73 \\
E & 19.82 & 13.02 & 16.04 & 26.36 & 24.33 & 130.24 \\
PAOC & 2.45 & 3.66 & 153.47 & 11.32 & 11.44 & 226.33 \\
PACE & 6.42 & 9.22 & -61.06 & 13.19 & 14.57 & 135.33 \\
\hline
\end{tabular}

Variable Definitions:

$\mathrm{Y}=$ Total value of Shipments - Output (millions of dollars)

$\mathrm{K}=$ Capital Stock (millions of dollars)

$\mathrm{L}=$ Production Worker Hours (thousands of hours)

$M=$ Cost of Raw Materials (millions of dollars)

$E=$ Value of Energy Consumed (millions of dollars)

$\mathrm{PAOC}=$ Pollution Abatement Operating Cost (millions of dollars)

$\mathrm{PACE}=$ Pollution Abatement Capital Expenditure (millions of dollars)

Table 2. Summary Statistics for Pulp and Paper Mills Emission

\begin{tabular}{lcccc}
\hline & Mean in 1974 & SD in 1974 & \% Growth in Mean 1974-1982 & Number of Observations \\
\hline Solid Waste & 37.36 & 58.42 & 0.78 & 37 \\
Abated PM & 26.83 & 38.95 & 0.59 & 67 \\
\hline
\end{tabular}

Table 3. Summary Statistics for Other Pollutants

\begin{tabular}{ccccc}
\hline & Mean in 1994 & SD in 1994 & \% Growth in Mean 1994-1998 & Number of Observations \\
\hline Paper BOD & 3147.91 & $(3152.75)$ & -0.38 & 81 \\
Paper TSS & 7496.15 & $(16000.00)$ & -0.51 & 81 \\
Paper TRI & 1151.58 & $(856.04)$ & 0.06 & 81 \\
Oil BOD & 170.53 & $(270.34)$ & -0.24 & 31 \\
Oil TSS & 270.64 & $(431.88)$ & -0.31 & 31 \\
\hline
\end{tabular}

${ }^{* * *}$ All emissions are reported in millions of tons

\footnotetext{
${ }^{16}$ Summary statistics are presented for 1974 with average growth for the 20 years under analysis. Detailed year by year summary statistics tables for all variables are available upon request from the author. All following results of the analysis including the figures and tables are provided for alternate years for brevity. Results for years that have been omitted are very similar to the ones included in the tables. A detailed year-by-year table of all results is available upon request from the author
} 


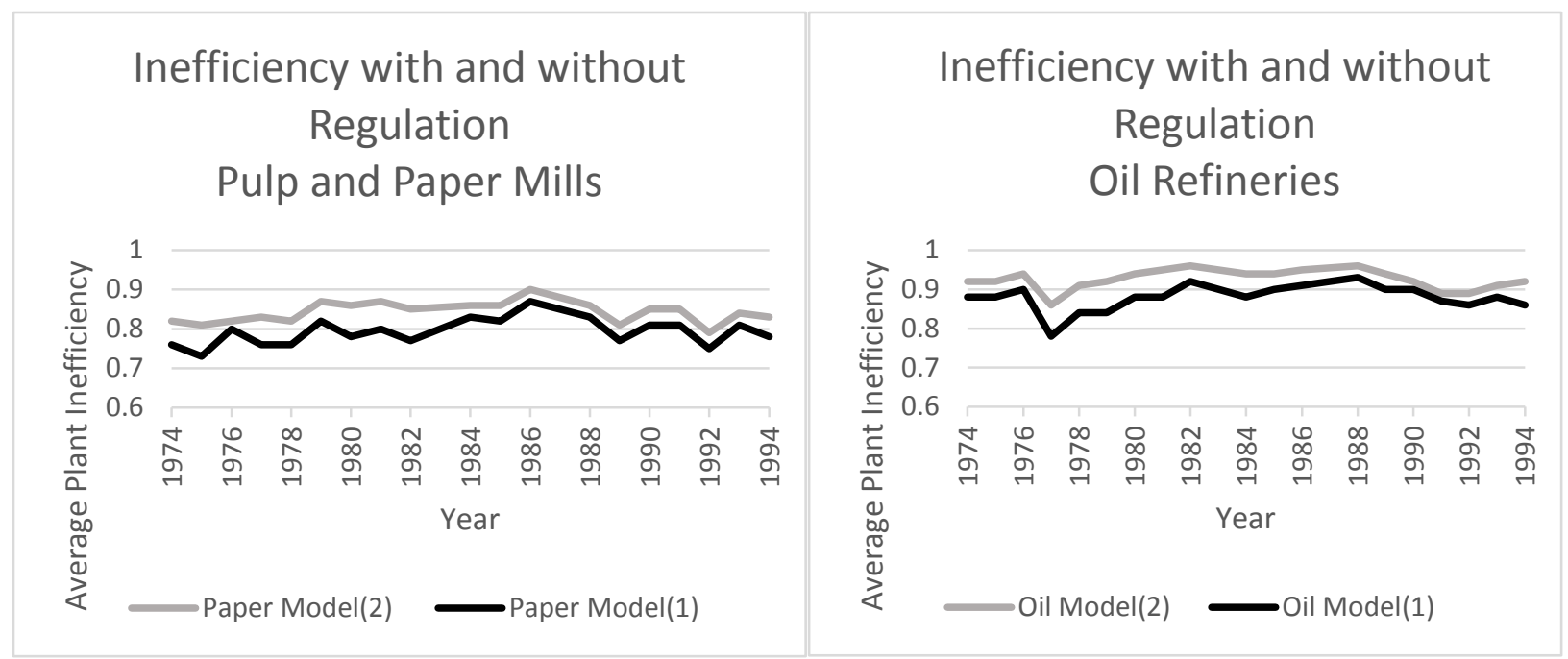

Figure 1 and 2: Figures show difference in the average efficiency scores from estimation models (1) and (2) [efficiency for plants with and without regulations] for pulp and paper mills and oil refineries.

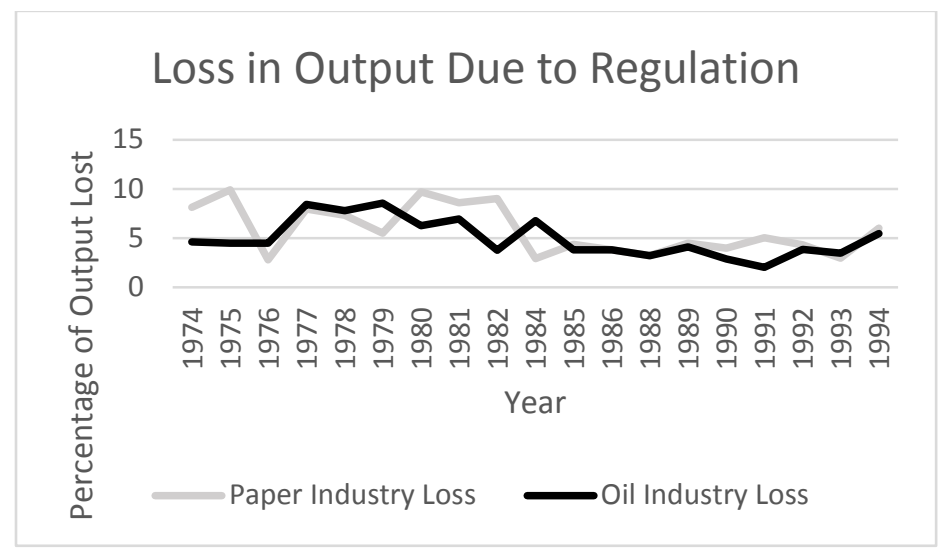

Figure 3: Figure shows the average loss per year arising out of environmental regulations for the pulp and paper mills and oil refineries between 1974 and 1994.

TABLE 4: Output Loss from Reg. using Solid Waste Emission Data- PACE (Pulp and Paper Mills)

\begin{tabular}{cccc}
\hline Year & Unregulated Eff. & Regulated Eff. & Output Loss \\
\hline 1974 & 0.83 & 0.87 & 4.28 \\
& $(0.13)$ & $(0.13)$ & $(5.63)$ \\
1976 & 0.82 & 0.88 & 6.09 \\
& $(0.13)$ & $(0.13)$ & $(9.50)$ \\
1978 & 0.82 & 0.88 & 6.87 \\
& $(0.12)$ & $(0.12)$ & $(7.47)$ \\
1980 & 0.84 & 0.88 & 4.39 \\
& $(0.13)$ & $(0.13)$ & $(7.58)$ \\
1982 & 0.91 & 0.94 & 3.30 \\
& $(0.11)$ & $(0.10)$ & $(5.30)$ \\
\hline
\end{tabular}

Mean values are reported with standard deviations in parenthesis. 
TABLE 5: Output Loss from Regulations using Other Emissions Data (Pulp and Paper Mills)

\begin{tabular}{cccccccccc}
\hline Year & BOD Unreg & BOD Reg & BOD Loss & TSS Unreg & TSS Reg & TSS Loss & TRI Unreg & TRI Reg & TRI Loss \\
\hline \multirow{2}{*}{1994} & 0.81 & 0.89 & 8.77 & 0.81 & 0.84 & 3.47 & 0.81 & 0.89 & 8.92 \\
& $(0.13)$ & $(0.12)$ & $(10.03)$ & $(0.13)$ & $(0.14)$ & $(6.15)$ & $(0.13)$ & $(0.12)$ & $(8.68)$ \\
\multirow{2}{*}{1996} & 0.87 & 0.90 & 3.97 & 0.87 & 0.90 & 4.03 & 0.87 & 0.90 & 3.39 \\
& $(0.12)$ & $(0.11)$ & $(5.88)$ & $(0.12)$ & $(0.11)$ & $(5.99)$ & $(0.12)$ & $(0.12)$ & $(4.07)$ \\
\multirow{2}{*}{1998} & 0.77 & 0.86 & 10.33 & 0.77 & 0.86 & 10.02 & 0.77 & 0.84 & 7.70 \\
& $(0.14)$ & $(0.12)$ & $(10.78)$ & $(0.14)$ & $(0.12)$ & $(9.87)$ & $(0.14)$ & $(0.14)$ & $(8.32)$ \\
\multirow{2}{*}{2000} & 0.79 & 0.83 & 4.91 & 0.79 & 0.84 & 6.14 & 0.79 & 0.86 & 8.13 \\
& $(0.14)$ & $(0.13)$ & $(8.23)$ & $(0.14)$ & $(0.13)$ & $(9.38)$ & $(0.14)$ & $(0.12)$ & $(8.78)$
\end{tabular}

Mean values are reported with standard deviations in parenthesis.

TABLE 6: Output Loss from Regulations using Other Emissions Data (Oil Refineries)

\begin{tabular}{ccccccc}
\hline Year & BOD Unreg & BOD Reg & BOD Loss & TSS Unreg & TSS Reg & TSS Loss \\
\hline \multirow{2}{1}{1994} & 0.80 & 0.85 & 5.53 & 0.80 & 0.87 & 7.89 \\
& $(0.14)$ & $(0.16)$ & $(7.59)$ & $(0.14)$ & $(0.13)$ & $(10.43)$ \\
1996 & 0.87 & 0.89 & 2.44 & 0.87 & 0.91 & 4.24 \\
& $(0.11)$ & $(0.11)$ & $(3.22)$ & $(0.11)$ & $(0.11)$ & $(5.38)$ \\
1998 & 0.89 & 0.92 & 4.26 & 0.89 & 0.93 & 5.13 \\
& $(0.10)$ & $(0.08)$ & $(5.22)$ & $(0.10)$ & $(0.08)$ & $(7.24)$ \\
1999 & 0.79 & 0.84 & 5.98 & 0.79 & 0.85 & 6.82 \\
& $(0.13)$ & $(0.12)$ & $(8.01)$ & $(0.13)$ & $(0.13)$ & $(6.46)$ \\
\hline
\end{tabular}

Mean values are reported with standard deviations in parenthesis.

TABLE 7: Output Loss from Regulations using Abated PM10 Data (Pulp and Paper Mills)

\begin{tabular}{cccc}
\hline Year & Unregulated Eff. & Regulated Eff. & Output loss \\
\hline \multirow{1}{1974}{} & 0.85 & 0.88 & 3.38 \\
& $(0.14)$ & $(0.13)$ & $(4.89)$ \\
1976 & 0.81 & 0.88 & 7.51 \\
& $(0.14)$ & $(0.13)$ & $(8.28)$ \\
1978 & 0.82 & 0.86 & 4.36 \\
& $(0.13)$ & $(0.13)$ & $(7.77)$ \\
1980 & 0.84 & 0.87 & 4.12 \\
& $(0.13)$ & $(0.12)$ & $(6.80)$ \\
1982 & 0.88 & 0.91 & 3.44 \\
& $(0.12)$ & $(0.11)$ & $(5.54)$ \\
\hline
\end{tabular}

Mean values are reported with standard deviations in parenthesis.

TABLE 8: Output Loss from Regulations using PACE Fixed-effects model

\begin{tabular}{ccccc}
\hline & Mean Loss & Std. Dev. & No. Obs. & Non FE Comparison \\
\hline PAPER & 3.00 & 2.30 & 1292 & 5.79 \\
OIL & 2.74 & 1.34 & 646 & 4.98 \\
\hline
\end{tabular}

Non FE Comparison: Measures of efficiency losses averaged across all years for each industry from figure 3. 
Table 9: Benefits and Losses from Regulation Abated PM - PACE (Pulp and Paper Mills)

\begin{tabular}{ccccc}
\hline & Avg. Loss (mil. \$) & Avg. Ben (mil. \$) & Tot. Loss (mil. \$) & Tot. Ben (mil. \$) \\
\hline \multirow{1}{19}{} & 5.95 & 14,400 & 398.77 & 966,000 \\
& $(10.50)$ & $(25,100)$ & & \\
\multirow{2}{*}{1976} & 12.34 & 17,700 & 826.83 & $1,190,000$ \\
& $(15.83)$ & $(23,200)$ & & \\
\multirow{2}{*}{1978} & 8.67 & 32,800 & 580.99 & $2,200,000$ \\
& $(17.80)$ & $(79,300)$ & & \\
\multirow{2}{*}{1980} & 7.36 & 39,400 & 493.38 & $2,640,000$ \\
& $(13.99)$ & $(47,500)$ & & $3,230,000$ \\
& 5.76 & 48,200 & 386.08 & \\
\hline
\end{tabular}

Mean values are reported with standard deviations in parenthesis.

Average measures refer to the average loss or benefit per plant each year whereas total measures refer to the total for the industry in that year.

Table 10: Is abatement cost overestimated or underestimated?

\begin{tabular}{lcccccc}
\hline Year & Oil (A) & Oil (B) & Oil (C) & Paper (A) & Paper (B) & Paper (C) \\
\hline $\mathbf{1 9 7 4}$ & 1.72 & 4.59 & 37.53 & 4.20 & 8.12 & 51.68 \\
1975 & 2.28 & 4.5 & 50.69 & 4.95 & 9.92 & 49.89 \\
1976 & 1.98 & 4.5 & 43.96 & 3.54 & 2.77 & 127.76 \\
1977 & 1.79 & 8.43 & 21.23 & 3.07 & 7.95 & 38.61 \\
1978 & 2.13 & 7.81 & 27.28 & 3.11 & 7.32 & 42.45 \\
1979 & 1.95 & 8.54 & 22.80 & 2.42 & 5.51 & 43.99 \\
1980 & 2.03 & 6.27 & 32.39 & 2.32 & 9.72 & 23.83 \\
1981 & 2.62 & 6.96 & 37.60 & 2.23 & 8.58 & 26.00 \\
1982 & 3.01 & 3.78 & 79.57 & 1.77 & 9.02 & 19.62 \\
1984 & 2.48 & 6.77 & 36.67 & 1.98 & 2.92 & 67.78 \\
1985 & 2.09 & 3.79 & 55.13 & 1.94 & 4.37 & 44.31 \\
1986 & 2.45 & 3.81 & 64.36 & 1.62 & 3.8 & 42.51 \\
1988 & 1.45 & 3.23 & 44.89 & 2.11 & 3.22 & 65.39 \\
1989 & 1.72 & 4.09 & 41.94 & 1.82 & 4.49 & 40.60 \\
1990 & 1.87 & 2.89 & 64.66 & 2.87 & 3.96 & 72.37 \\
1991 & 2.20 & 2.01 & 109.51 & 2.97 & 5.02 & 59.17 \\
1992 & 2.84 & 3.83 & 74.09 & 2.63 & 4.3 & 61.25 \\
1993 & 2.94 & 3.45 & 85.24 & 2.30 & 2.94 & 78.26 \\
1994 & 2.94 & 5.45 & 53.95 & 2.08 & 5.99 & 34.80 \\
\hline
\end{tabular}

Definition for Each Column:

(A): Abatement Cost Share for each industry

(B): Mean estimated Output Loss due to Regulation in each industry

(C): Percentage of Output Loss Explained by Abatement Expenditure in each industry 
Table 11: Is abatement cost overestimated or underestimated? - Fixed Effects Results

\begin{tabular}{ccccccc}
\hline & Oil (A) & Oil (B) & Oil (C) & Paper (A) & Paper (B) & Paper (C) \\
\hline FE & 2.24 & 2.74 & 81.75 & 2.63 & 3 & 87.67 \\
\hline $\begin{array}{c}\text { Non FE } \\
\text { Comparison }\end{array}$ & 2.24 & 4.98 & 51.76 & 2.63 & 5.79 & 52.12 \\
\hline
\end{tabular}

Definition for Each Column:

FE-

(A): Abatement Cost Share for each industry

(B): Mean estimated Output Loss due to Regulation in each industry

(C): Percentage of Output Loss Explained by Abatement Expenditure in each industry

Non FE Comparison- (brought in from cross-sectional analysis results in figure 3 \& Table 10)

(A): Average Abatement Cost Share for each industry across all years

(B): Average of the Mean estimated Output Loss due to Regulation in each industry across all years

(C): Average Percentage of Output Loss Explained by Abatement Expenditure in each industry across all years 


\section{References}

Aiken, D.V., R. Färe, S. Grosskopf, and C.A. Pasurka. 2009. "Pollution Abatement and Productivity Growth: Evidence from Germany, Japan, the Netherlands, and the United States." Environmental and Resource Economics no. 44 (1):11-28.

Asmild, M., J.C. Paradi, V. Aggarwall, and C. Schaffnit. 2004. "Combining DEA window analysis with the Malmquist index approach in a study of the Canadian banking industry." Journal of Productivity Analysis no. 21 (1):67-89.

Banker, R.D., A. Charnes, and W.W. Cooper. 1984. "Some models for estimating technical and scale inefficiencies in data envelopment analysis." Management science:1078-1092.

Banker, R.D., W.W. Cooper, L.M. Seiford, R.M. Thrall, and J. Zhu. 2004. "Returns to scale in different DEA models." European Journal of Operational Research no. 154 (2):345-362.

Barbera, A.J., and V.D. McConnell. 1986. "Effects of pollution control on industry productivity: a factor demand approach." The Journal of Industrial Economics:161-172.

Becker, R.A., and R.J. Shadbegian. 2007. "Issues and Challenges in Measuring Environmental Expenditures by US Manufacturing: The Redevelopment of the PACE Survey." NCEE Working Paper Series.

Berman, E., and L.T.M. Bui. 2001. "Environmental regulation and productivity: evidence from oil refineries." Review of Economics and Statistics no. 83 (3):498-510.

Boyd, G.A., and J.D. McClelland. 1999. "The impact of environmental constraints on productivity improvement in integrated paper plants." Journal of Environmental Economics and Management no. 38 (2):121-142.

Brännlund, R., R. Färe, and S. Grosskopf. 1995. "Environmental regulation and profitability: an application to Swedish pulp and paper mills." Environmental and Resource Economics no. 6 (1):23-36.

Charnes, A., WW Cooper, and E. Rhodes. 1978. "Measuring the efficiency of DMU." European Journal of Operational Research no. 2 (6):429-444.

Christainsen, G.B., and R.H. Haveman. 1981. "Public regulations and the slowdown in productivity growth." The American Economic Review no. 71 (2):320-325.

Chung, Yangho H, Rolf Färe, and Shawna Grosskopf. 1997. "Productivity and undesirable outputs: a directional distance function approach." Journal of environmental management no. 51 (3):229240.

Cook, W.D., and L.M. Seiford. 2009. "Data envelopment analysis (DEA)-Thirty years on." European Journal of Operational Research no. 192 (1):1-17.

Denison, E.F. 1979. Accounting for slower economic growth: the United States in the 1970's: Brookings Institution Press.

Färe, R., and S. Grosskopf. 2000. "Theory and application of directional distance functions." Journal of Productivity Analysis no. 13 (2):93-103.

Färe, R., S. Grosskopf, C.A.K. Lovell, and C. Pasurka. 1989. "Multilateral productivity comparisons when some outputs are undesirable: a nonparametric approach." The review of economics and statistics no. 71 (1):90-98.

Färe, R., S. Grosskopf, and C.A. Pasurka. 2007. "Pollution abatement activities and traditional productivity." Ecological Economics no. 62 (3-4):673-682.

Fare, R., and CA Knox Lovell. 1978. "Measuring the technical efficiency of production." Journal of Economic Theory no. 19 (1):150-162.

Farrell, M.J. 1957. "The measurement of productive efficiency." Journal of the Royal Statistical Society. Series A (General) no. 120 (3):253-290. 
Gollop, F.M., and M.J. Roberts. 1983. "Environmental regulations and productivity growth: The case of fossil-fueled electric power generation." The Journal of Political Economy:654-674.

Gray, W.B, and R.J. Shadbegian. 2002. "Pollution abatement costs, regulation, and plant-level productivity." In The Economic Costs and Consequences of Environmental Regulation., W.B. Gray (Ed.). Ashgate Publications, Aldershot, UK.

Gray, W.B. 1987. "The cost of regulation: OSHA, EPA and the productivity slowdown." The American Economic Review no. 77 (5):998-1006.

Gray, W.B., and R.J. Shadbegian. 2003. "Plant vintage, technology, and environmental regulation." Journal of Environmental Economics and Management no. 46 (3):384-402.

Gray, W.B., and R.J. Shadbegian. 2004. "'Optimal'pollution abatement-whose benefits matter, and how much?" Journal of Environmental Economics and Management no. 47 (3):510-534.

Greenstone, M. 2002. "The impacts of environmental regulations on industrial activity: Evidence from the 1970 and 1977 clean air act amendments and the census of manufactures." Journal of political economy no. 110 (6):1175-1219.

Greenstone, Michael, John A List, and Chad Syverson. 2012. The effects of environmental regulation on the competitiveness of US manufacturing. National Bureau of Economic Research.

Griliches, Zvi, and Jacques Mairesse. 1995. Production functions: the search for identification. National Bureau of Economic Research.

Morgenstern, R.D., W.A. Pizer, and J.S. Shih. 2001. "The cost of environmental protection." Review of Economics and Statistics no. 83 (4):732-738.

Norsworthy, J.R., M.J. Harper, and K. Kunze. 1979. "The slowdown in productivity growth: Analysis of some contributing factors." Brookings Papers on Economic Activity no. 1979 (2):387-421.

Palmer, K., W.E. Oates, and P.R. Portney. 1995. "Tightening environmental standards: The benefit-cost or the no-cost paradigm?" The Journal of Economic Perspectives no. 9 (4):119-132.

Ringquist, E.J. 1993. Environmental protection at the state level: Politics and progress in controlling pollution: ME Sharpe.

Seiford, L.M., and J. Zhu. 2002. "Modeling undesirable factors in efficiency evaluation." European Journal of Operational Research no. 142 (1):16-20.

Seiford, Lawrence M., and Joe Zhu. 2005. "A response to comments on modeling undesirable factors in efficiency evaluation." European Journal of Operational Research no. 161 (2):579-581.

Shadbegian, R.J., and W.B. Gray. 2005. "Pollution abatement expenditures and plant-level productivity: A production function approach." Ecological Economics no. 54 (2-3):196-208.

Shadbegian, R.J., and W.B. Gray. 2006. "Assessing multi-dimensional performance: environmental and economic outcomes." Journal of Productivity Analysis no. 26 (3):213-234.

Shephard, Ronald W, David Gale, and Harold W Kuhn. 1970. Theory of cost and production functions: Princeton University Press Princeton, NJ.

Shestalova, V. 2003. "Sequential Malmquist indices of productivity growth: An application to OECD industrial activities." Journal of Productivity Analysis no. 19 (2):211-226.

Shimshack, J.P., and M.B. Ward. 2005. "Regulator reputation, enforcement, and environmental compliance." Journal of Environmental Economics and Management no. 50 (3):519-540.

Shimshack, J.P., and M.B. Ward. 2008. "Enforcement and over-compliance." Journal of Environmental Economics and Management no. 55 (1):90-105.

Simar, Leopold, and Paul W Wilson. 2007. "Estimation and inference in two-stage, semi-parametric models of production processes." Journal of econometrics no. 136 (1):31-64.

Wilson, P.W. 1993. "Detecting outliers in deterministic nonparametric frontier models with multiple outputs." Journal of Business \& Economic Statistics:319-323. 